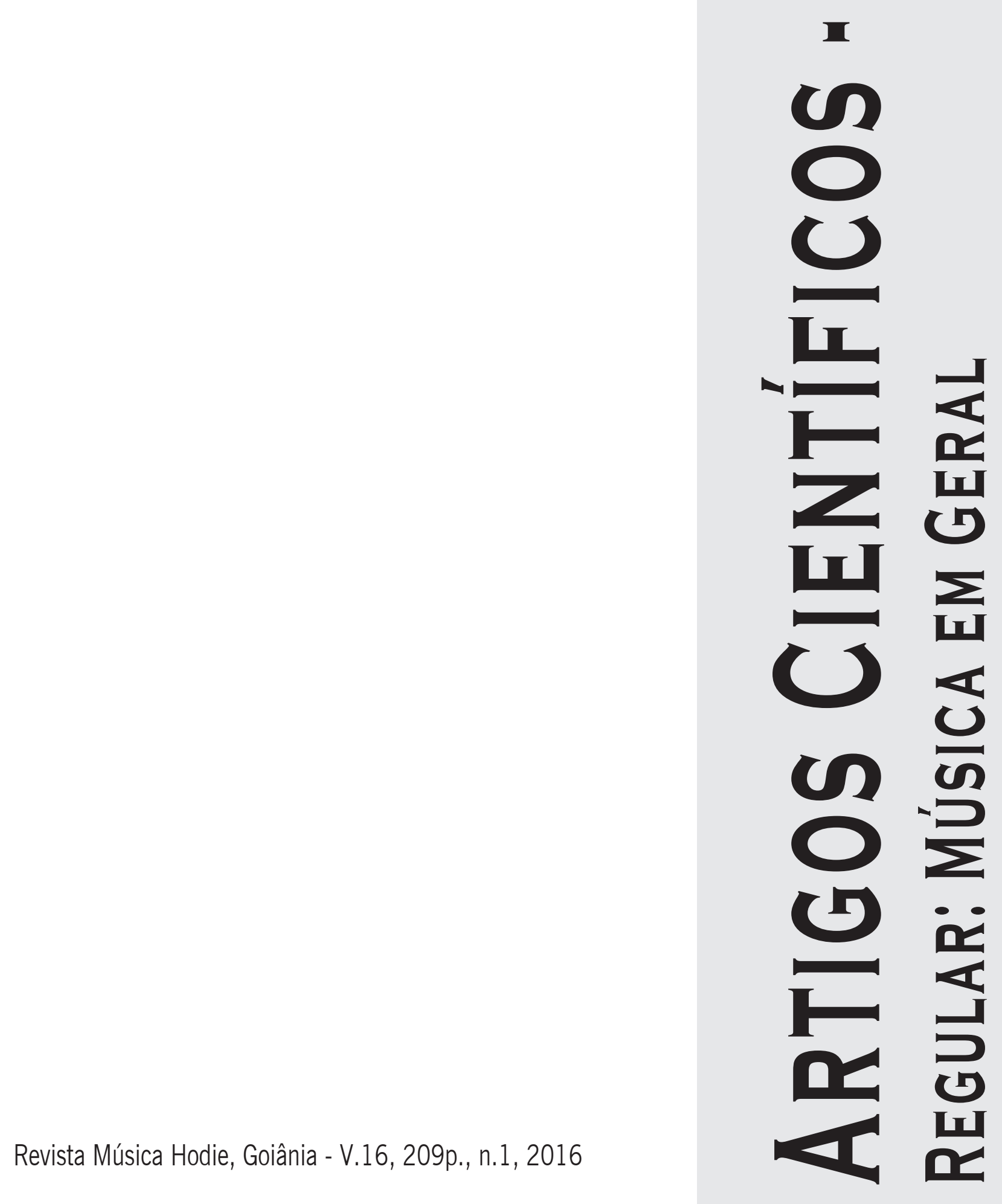




\title{
Aplicação de conceitos da psicologia cognitiva na construção de automatismos na leitura musical
}

\author{
Danilo Bogo (Faculté de Musique, Université de Montréal, Montreal, Canadá) \\ danilobogo@gmail.com
}

\begin{abstract}
Resumo: Este artigo discute a influência da psicologia cognitiva no processo de ensino-aprendizagem da leitura musical visando melhorar o desempenho da leitura à primeira vista. Reconhecendo a importância de respostas cinestésicas automatizadas aos estímulos visuais, o objetivo deste artigo é apresentar alguns conceitos da psicologia cognitiva que podem ser usados para facilitar a construção de automatismos aptos a serem evocados numa tarefa de leitura musical. Para isso, será apresentado a arquitetura cognitiva relacionada a uma tarefa de leitura musical. Em seguida, mostraremos a importância dos automatismos na leitura e abordaremos algumas práticas influenciadas pela psicologia cognitiva. Entre os conceitos abordados estão tipos de conhecimento, metacognição, codificação dupla, transferência de conhecimento e chunking. Conclui-se que um melhor conhecimento do nosso processo cognitivo pode influenciar as estratégias de ensino/aprendizagem na leitura musical.
\end{abstract}

Palavras-chave: Cognição; Leitura musical à primeira vista; Automatismos na leitura musical.

Applying cognitive psychology to build music-reading automatisms

Abstract: This article discusses the influence of cognitive psychology on the teaching-learning process of reading music, aiming to improve sight-reading performance. Acknowledging the importance of automatic kinesthetic response upon visual stimuli, the purpose of this article is to present some concepts from cognitive psychology that may be used to facilitate the construction of automatisms able to be evoked while reading music. In this regard, it is presented a cognitive architecture related to a musical reading task. Subsequently, we demonstrate the automatisms' importance for reading and explore some practices influenced by cognitive psychology. Among the studied concepts are types of knowledge, dual coding theory, metacognition, knowledge transfer and chunking. The conclusion shows that better understanding one's cognitive processes may affect teaching-learning strategies in music reading.

Keywords: Cognition; Music sight-reading; Automatisms in music sight-reading.

Aplicación de conceptos de la psicología cognitiva en la construcción de automatismos en la lectura musical

Resumen: Este artículo discute la influencia de la psicología cognitiva en el proceso de enseñanza-aprendizaje de la lectura musical buscando mejorar el desempeño de la lectura a primera vista. Reconociendo la importancia de respuestas cinestésicas automatizadas a los estímulos visuales, el objetivo de este artículo es presentar algunos conceptos de la psicología cognitiva que pueden ser usados para facilitar la construcción de automatismos aptos para ser evocados en una tarea de lectura. Para eso, será presentada la arquitectura cognitiva relacionada a una tarea de lectura musical. En seguida, mostraremos la importancia de los automatismos en la lectura y abordaremos algunas prácticas influenciadas por la psicología cognitiva. Entre los conceptos abordados están tipos de conocimiento, metacognición, codificación doble, transferencia de conocimiento y chunking. Se concluye que una mejor comprensión de nuestro proceso cognitivo puede influir en las estrategias de enseñanza-aprendizaje de la lectura musical.

Palabras clave: Cognición; Lectura musical a primera vista; Automatismos en la lectura musical.

Encontrar uma boa definição para o termo leitura à primeira vista pode se mostrar uma tarefa difícil se considerarmos alguns pontos, por exemplo: se fizermos um pré-exame da partitura, tentando tocar as partes mais difíceis e predefinindo digitações, ainda estaremos fazendo uma leitura à primeira vista? Se já escutei a peça, isto é, se sei como ela soa, poderíamos ainda falar de leitura à primeira vista? Se eu já toquei a peça há muito tempo - e mesmo se não lembro como tocá-la hoje - poderíamos ainda falar de leitura à primeira vista? Não sendo o objetivo deste artigo discutir essas questões - mesmo que relevantes - assumiremos uma definição mais direta do termo proposta por GABRIELSSON (2003, p. 243) "Leitura à primeira vista significa a performance a partir de uma partitura sem nenhuma prática precedente no instrumento para o qual a peça foi escrita, tocar a prima vista"”.

Lehmann e Mcarthur (2002, p. 136) falam da importância dessa habilidade no fazer musical. Os autores citam como exemplo os exames de admissão para pianista acompanha- 
dor; os músicos de orquestra ou de estúdio que não têm muito tempo para praticar suas partes; a escolha de repertório de grupos instrumentais ou vocais onde o maestro vai frequentemente "testar", isto é, ver como soa uma determinada peça fazendo uma leitura; e por fim, a prática diária dos músicos que escolhem seu repertório lendo várias peças à primeira vista antes de decidir o que estudar.

Um fator que influencia fortemente a leitura musical é a capacidade de dar uma resposta automatizada ao estímulo visual (partitura) permitindo que o discurso não seja interrompido. Assim, o objetivo deste artigo é apresentar alguns conceitos da psicologia cognitiva que podem ser utilizados no processo de ensino-aprendizagem visando facilitar a construção de automatismos aptos a serem evocados numa leitura à primeira vista. Segundo Tardif (1992), a psicologia cognitiva se interessa nos mecanismos de construção gradual dos conhecimentos na memória, nas condições de reutilização desses conhecimentos, nas estratégias de aprendizagem do aluno e nas estratégias de ensino.

Desta forma, primeiro será apresentada a arquitetura cognitiva e sua abordagem numa tarefa de leitura musical. Em seguida, mostraremos a importância dos automatismos na leitura e abordaremos práticas influenciadas pela psicologia cognitiva que podem ajudar a criar automatismos de leitura.

\section{Arquitetura cognitiva}

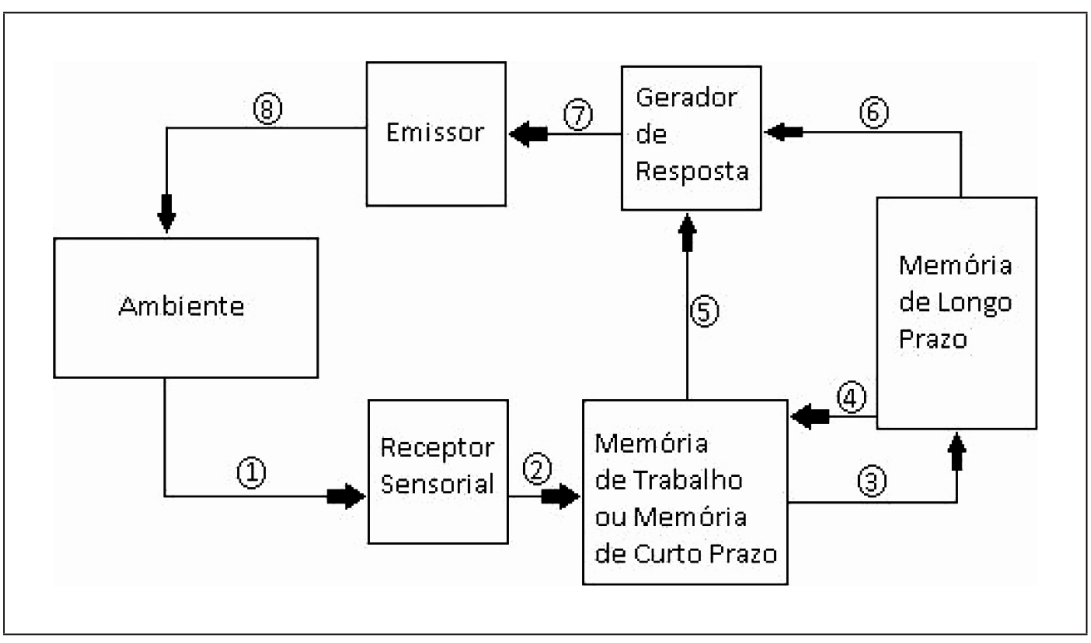

Figura 1: Elementos da arquitetura cognitiva com o caminho que a informação percorre (seguindo os números das flechas em ordem crescente). Fonte: Tardif (1992, p. 163).

Esse modelo de compreensão da arquitetura cognitiva, Figura 1, apresentado sob uma ótica construtivista é a tradução da mesma figura apresentada por Tardif (1992, p. 163). Os números das flechas indicam o caminho que a informação percorre. Todo o processo começa por estímulos que provêm do ambiente (ou do pensamento) e são captados pelos receptores sensoriais, se dirigindo em seguida ao registro sensorial. Neste ponto, um filtro baseado nos conhecimentos já adquiridos separa as informações eliminando o que não deverá ser retido. $\mathrm{O}$ que passa por esse filtro atinge a memória de trabalho (MT), a qual interpreta as informações lhes dando sentido. A MT faz a ponte entre as informações armazenadas na memória de longo prazo (MLP) e as novas informações que recebemos (flechas 3 e 4). Segundo Miller (1956), a MT pode reter até 7 unidades de informação que desaparecem ao fim de 10 segundos. O chunking ${ }^{2}$ permite contornar esse limite reagrupando o conhecimento que será tratado como uma só unidade de informação. 
A memória de longo prazo (MLP) guarda os conhecimentos afetivos, sociais, motores e intelectuais, assim como os automatismos, isto é, o que podemos fazer sem sobrecarregar a memória de trabalho (MT). Existem dois tipos de MLP: a episódica ou autobiográfica (lembranças pessoais), e a semântica (conceitos, leis, regras, princípios, procedimento e condições). Desta forma, primeiro recebemos as novas informações e as comparamos às existentes (tudo isso na MT). Depois, fazemos ligações entre antigas e novas informações, o que nos permitirá registrar essa nova cadeia de informações - agora amplificada - na MLP.

Para que a informação se transforme em conhecimento, ela deve antes ser tratada pelo sistema cognitivo. Segundo Anderson (1985) e Marzano et al. (1988) existem três tipos de conhecimento: conhecimento declarativo (noções puramente teóricas), procedural (sequência de ações mais ou menos longa) e condicional (onde e quando os conhecimentos declarativos e procedurais devem ser utilizados). Esses três tipos de conhecimento não são dissociados uns dos outros na MLP, mas são, ao contrário, organizados hierarquicamente em esquema. Uma boa organização desse esquema favorece a evocação e a reprodução dos conhecimentos adquiridos, assim como a aquisição de novas informações que têm por base conhecimentos anteriores.

O item emissor presente na Figura 1 representa os músculos e as membranas que permitem uma resposta aos estímulos (GAGNÉ, 1985 apud HEROUX, 2006). Desta forma, após a informação ser tratada pelas MT e MLP, ela atinge o gerador de resposta que controla o emissor - isto é braços, dedos, cordas vocais, etc. Tardif (1992, p. 177) sustenta que o gerador de respostas utiliza mais espaço da MT quando os conhecimentos procedurais e condicionais não estão automatizados. Se o conhecimento está automatizado, ele pode passar quase diretamente da MLP ao gerador de resposta (flecha 6 da Figura 1). O autor acredita que no caso de um conhecimento automatizado - levando em conta alguém experiente -, o espaço ocupado da memória de trabalho para a realização de uma tarefa será bem limitado, provavelmente de uma unidade de informação (p. 357).

Antes de terminar essa breve descrição do processo cognitivo cabe apresentar dois conceitos importantes que serão melhor detalhados posteriormente. O primeiro deles é o conceito de transferência de conhecimento que faz referência a uma informação geral armazenada que será utilizada em um outro contexto (recontextualização) para desenvolver um novo conhecimento. Ou seja, mais que lembrar de um conhecimento já adquirido, essa informação geral, ao entrar em contato com outra informação em outro contexto, gera um novo conhecimento e modifica a MLP (TARDIF, 1992). O segundo conceito é a metacognição que pode ser entendida, nesse contexto, como a capacidade de refletir e de monitorar a qualidade do próprio resultado de uma tarefa. É a consciência, a organização e a auto avaliação do nosso processo cognitivo (ANDRETTA et al., 2010)

\section{Memória na leitura à primeira vista}

Consideremos o exemplo de estímulo visual apresentado abaixo (Figura 2), ao qual iremos comparar uma atitude "ideal" entre um leitor experiente e um iniciante. Para realizar essa tarefa, imaginaremos dois comportamentos extremos diante do estímulo: o melhor e o pior. 


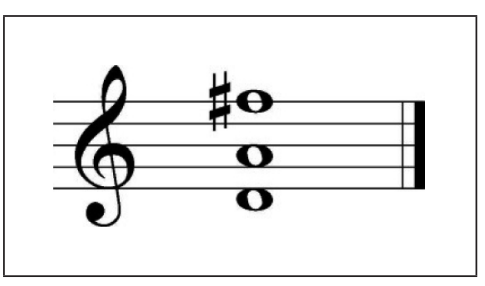

Figura 2: Acorde de Ré maior em uma disposição que pode ser executado por variados instrumentos harmônicos. Fonte: Figura elaborada pelo autor.

Para iniciar, percorreremos o caminho que o estímulo faz na arquitetura cognitiva até sua saída como som. Percebido no ambiente, o estímulo passa pelos receptores sensoriais (nesse caso os olhos) que captam e filtram as informações deixando passar apenas o que seria importante para a realização da tarefa. Essa informação chega a MT que consulta a MLP verificando se essa informação já está registrada. A partir da resposta, a MT deve tomar uma decisão em relação à tarefa e enviar essas informações ao gerador de resposta. Este último comandará os emissores (braço, dedos etc.) que executarão os movimentos cinestésicos necessários para tocar o acorde dado que será percebido no ambiente agora como som.

A diferença entre um experiente e um leitor iniciante se situa, sobretudo, a partir do momento que a informação chega a MT. Nesse momento, a utilização de conhecimentos declarativos (um acorde de Ré maior escrito na clave de Sol) e procedurais (onde colocar os dedos para se tocar o acorde) é necessária. O leitor iniciante verá cada uma das notas do acorde (Ré, Lá e Fá\#) separadamente (declarativo) e tentará encontrar essas notas no instrumento (procedural), o que vai certamente sobrecarregar a MT. Considerando que ele não tem em sua MLP a certeza do resultado sonoro deste estímulo visual, ele não poderá, assim, saber se o resultado da tarefa foi bem sucedido ou bem compreender como chegou a esse resultado (metacognição). Por outro lado, no caso de um leitor experiente, ele reconhecerá esse estímulo como uma unidade de informação, isto é, um acorde (um chunk). Ele terá assim uma resposta cinestésica automatizada ao estímulo. O som produzido chegará igualmente à MT confirmando a sonoridade de Ré maior (já registrada na MLP) validando a boa realização da tarefa.

Analisando a diferença da distância entre o olho e a mão (eye-hand span ${ }^{3}$ em leitores profissionais e amadores numa tarefa de leitura, Furneaux e Land (1999) observaram que os profissionais tinham uma MT mais desenvolvida que os amadores, pois eles foram capazes de guardar mais informações (1,4 notas a mais) no mesmo índice-tempo de cerca de $1 \mathrm{seg}$. Os pesquisadores não acreditam que isso se deva ao fato dos profissionais terem um buffer ${ }^{4}$ maior, mas sobretudo, porque eles são capazes de reagrupar (chunking) várias notas e tratá-las como uma só unidade de informação. Essa teoria é também sustentada por Sloboda (2005), Comeau (2009) e Dehaene (2007). Esta capacidade estaria relacionada a uma melhor percepção do que poderíamos chamar de "gramática musical". Uma comparação com a leitura de textos faz-se inevitável. Por exemplo, é mais difícil ler a palavra "lavandicarens" que "profissionais". Mesmo se ambas têm o mesmo número de letras, a primeira palavra não existe, quer dizer, não faz parte do léxico português (nem de outra língua). Assim, é necessário parar em cada sílaba, obrigando-nos a fazer várias fixações oculares e ao final a mesma não está registrada na nossa MLP.

É muito difícil estabelecer um léxico musical, pois ele muda segundo a época, o gênero e o estilo. Por outro lado, uma grande parte do repertório de qualquer instrumento é baseada em alguns elementos mais comuns (como escalas, acordes, motivos, cadências etc.) que se mostram mais facilmente reconhecíveis por leitores experientes. 


\section{Importância dos automatismos}

Como visto acima, no caso de um conhecimento procedural ou condicional automatizado, a memória de longo prazo (MLP) pode controlar diretamente o gerador de resposta (flecha 6 da Figura 1), liberando espaço da memória de trabalho (MT) (TARDIF, 1992, p. 173). Estes automatismos podem ser chunks, isto é, quando pensamos num acorde ou numa escala dada, por exemplo, não pensamos em todas as notas que os constituem, mas em uma só unidade de informação que engloba as mesmas. Não podemos esquecer também que, no caso dos instrumentos de corda, esses automatismos estão ligados a uma condição: a posição no braço do instrumento na qual montaremos o acorde. Tardif (1992, p. 175) sustenta que um papel importante do professor "é fazer com que os conhecimentos que podem ser automatizados pelo aluno sejam feitos o mais rápido possível afim que ele possa empregar suas unidades de memória de trabalho nos elementos mais significativos da tarefa ${ }^{5}$ ". Esses elementos mais significativos em música podem ser a sonoridade, o fraseado, a dinâmica, o discurso musical, etc.

Quando realizamos uma leitura à primeira vista, o reconhecimento e a reprodução de padrões automatizados (como escalas, arpejos, acordes, cadências etc.) são necessários para termos uma tomada de decisão rápida permitindo que o discurso musical seja

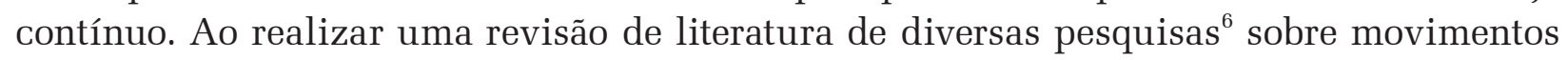
dos olhos na leitura musical, Madell e Hebert (2008, p. 166) observaram que a fixação ${ }^{7}$ dos olhos na partitura de leitores experientes é mais curta e mais frequente que de iniciantes que levam mais tempo pra determinar o que devem tocar. Isso nos mostra que os melhores leitores são mais rápidos na tomada de decisão, pois eles ficam menos tempo com os olhos fixados em um local específico da partitura. Isto nos sugere também que os leitores mais experientes têm uma gama de automatismos mais desenvolvidos e são capazes de dar uma significação mais profunda a uma passagem, enquanto os menos experientes têm a tendência a ler nota por nota sem reconhecer as relações entre elas (Lehmann e Mcarthur, 2002, p. 140). Revisando outra literatura ${ }^{8}$, Fireman (2010) observa que o resultado de uma tarefa de leitura à primeira vista é melhor quando os leitores são capazes de reconhecer padrões dentro de uma coerência tonal mostrando que é mais fácil repetir padrões automatizados apreendidos que decodificar novas informações.

Além de comparar comportamentos estereotipados entre leitores experientes ou não uma pergunta mais importante se põe: como a psicologia cognitiva pode ajudar leitores iniciantes a desenvolver seus automatismos de leitura?

\section{Influência na prática pedagógica}

Acreditamos que um papel importante do professor de instrumento é ajudar na construção e evocação de automatismos de leitura. Como citado acima, em música isso significaria trabalhar a leitura de escalas, intervalos, acordes, cadências, etc. em diferentes tonalidades e em diferentes posições/digitações no instrumento até que os mesmos se tornem automatizados. $\mathrm{O}$ estudo do nosso processo cognitivo pode nos dar alguns direcionamentos de como trabalhar esses elementos.

Como mencionado acima, os conhecimentos declarativos, procedurais e condicionais não são dissociados uns dos outros, mas, ao contrário, se relacionam em cadeia, sendo interligados em redes. Assim, o acorde da Figura 2 pode ser relacionado aos três tipos de conhecimento ao mesmo tempo: conhecimento declarativo (acorde de Ré maior em semi- 
breve escrito numa clave de sol etc.); procedural (quais movimentos cinestésicos são necessários para executar o acorde); e condicional (porque usar uma digitação/posição específica). Quanto mais as informações são ancoradas entre esses três tipos de conhecimento mais elas serão passíveis de serem reutilizadas (HEROUX 2006, p. 129).

Dentro de um mesmo tipo de conhecimento, as informações são interligadas também entre si e muitas vezes de maneira hierárquica. Como exemplo disso, em relação aos conhecimentos declarativos, podemos analisar como relacionamos as figuras musicais na leitura, por exemplo, uma semibreve vale duas mínimas, uma mínima vale duas semínimas que valem quatro colcheias, oito fusas e assim por diante. Da mesma forma, quando vemos uma nota Si no centro do pentagrama sabemos que o Dó está acima e o Lá abaixo. Assim, ao organizarmos as informações umas em relação às outras de maneira hierárquica criamos ancoras que nos ajudam na recuperação dessas informações. O mesmo não seria facilitado quando a informação é desprovida de comparação.

Em relação aos conhecimentos procedurais, Heroux (2006, p. 123) explica que estes "servem na verdade para pôr em funcionamento os conhecimentos declarativos",. Assim, o procedimento para tocar uma mínima de Dó escrita no centro do pentagrama (declarativo) no violão, por exemplo, é colocar o dedo um da mão esquerda na segunda corda da primeira casa no braço do instrumento; pinçar a segunda corda com o indicador da mão direita (procedural); e esperar que a nota vibre dois tempos. Essa descrição detalhada também revela uma organização dos movimentos em cadeia que deve ser automatizada para não sobrecarregar a MT.

Aos conhecimentos condicionais estão relacionados o como, onde, quando e porque devemos utilizar um conhecimento específico. Se voltarmos ao exemplo da Figura 2, deveremos adaptar nossos emissores à posição/digitação necessária para realizar o acorde. Assim, ao ver um estímulo visual teremos que decidir em qual posição (no caso dos instrumentos de corda) executar, com qual digitação, etc. No violino, por exemplo, o mesmo acorde da Figura 2 poderia ser montado na posição I ou IV; no violão na I, V ou X, ambos com variadas digitações. No caso dos instrumentos de teclas, como só há uma tecla relacionada a uma nota, os conhecimentos condicionais estariam relacionados apenas à digitação, isto é, com quais dedos realizar o acorde.

Em relação à aquisição de conhecimentos procedurais e condicionais, Tardif (1992, p. 356) afirma que "é através da ação e pela ação que a aquisição desses conhecimentos têm maior probabilidade de se produzir ${ }^{10}$ ”. O autor sustenta ainda que as intervenções pedagógicas, no caso de um conhecimento procedural, "consistem assim em tornar a sequência de ações disponível ao campo perceptivo do aluno ${ }^{11 "}$ (p. 359). O procedimento (sequência de ações necessária para a realização de uma tarefa) deve então ser assimilado e disponível na memória para que o aluno possa "consultar cada vez que isso for necessário para a ação ${ }^{12}$ ” (p. 359). Ainda falando sobre o papel do professor nesse processo, o mesmo autor pondera que "o educador estratégico vai assim colocar o aluno num contexto de prática guiada onde ele deve efetuar o conhecimento procedural do começo ao fim ${ }^{13}$ ” (p. 363).

Vimos até aqui como a informação pode ser organizada entre conhecimentos diferentes (declarativo, procedural e condicional) e dentro de um mesmo tipo de conhecimento. Vimos também um pouco do papel do professor nesse processo. Apresentando outra abordagem, Paivio (1975) fala de como a informação é representada na memória. O autor acredita que a informação é processada por dois canais: um verbal e outro pictórico. Assim, a palavra árvore, por exemplo, nos conecta a imagem do objeto (uma árvore). Ou ao contrário, uma imagem de árvore nos remete a palavra que a representa. Em seus testes, Paivio além de provar que imagens são mais suscetíveis de serem relembradas do que palavras, nos 
mostrou que uma imagem apresentada ao lado do seu nome era mais fácil de ser relembrada do que somente imagem ou somente palavra. Assim, palavras abstratas (que não podem ser relacionadas à imagens) são também mais difíceis de serem lembradas. O autor chama esse processo de teoria da codificação dupla (Dual coding theory ${ }^{14}$ ).

Heroux (2006) sugere a teoria da codificação dupla relacionada ao ensino da leitura musical. Entretanto, a autora coloca a dificuldade específica desta prática ao defender que além da representação pictórica (partitura) e verbal (nome de nota, duração etc.) temos a memória auditiva (frequência da nota) e cinestésica (memória de movimento). Lamentando não haver ainda pesquisas sobre uma possível "múltipla codificação", a autora espera que esta seja aplicada numa pesquisa futura sobre a leitura musical.

Em seu plano de trabalho visando desenvolver a leitura musical ao violão, Bogo (2013) encoraja uma prática de tocar e cantar as notas que se leem. Essa prática - influenciada pelas ideias de Paivio (1975) e Heuroux (2006) - sugere uma espécie de múltipla codificação, justapondo representações verbais, visuais, auditivas e cinestésicas. Essa prática também é vista em outros livros/métodos que se dedicam à leitura. Hunt (1977, p. 8) em seu método de leitura pra violão sustenta que o ato de "verbalizar fixa a informação na memória, dá mais controle e permite ao aluno aprender mais rápido ${ }^{15 ”}$. Ele pede ao estudante para tocar de três formas: dizendo o nome da nota (logo antes de tocar), dizendo a digitação da mão direita e por último, a da mão esquerda. Richman (1985, p. 11), no seu método de leitura para piano, também sustenta que "a repetida verbalização de cada nota estimula a rápida memorização ${ }^{16 "}$.

A prática de verbalizar também é defendida por outros autores, porém, neste caso, como uma estratégia metacognitiva. Como vimos acima, entende-se por metacognição a qualidade de refletir, de monitorar e de criar estratégias que auxiliarão a própria aprendizagem. Para Andretta et al. (2010, p. 10) seria uma prática de "explicar pra si mesmo" de "monitorar a compreensão". Os autores a chamam de "pensar alto”, isto é, descrever as ações necessárias para realizar uma tarefa durante sua execução com o intuito de auxiliar o aluno a achar soluções. Isso vai de encontro com o que Hunt (1977) defende ao encorajar a verbalização da digitação, por exemplo. Outro ponto essencial na leitura que serve de prova que uma tarefa foi bem executada é a capacidade de imaginar um som a partir da notação. O termo preciso que descreve essa habilidade é a audiação notacional. Por esse termo entende-se a capacidade de ouvir o som a partir da notação e de lhe dar um significado sintático, isto é, na mente, antes de ser tocado no instrumento (GORDON, 1999, p. 42). Apesar da audiação ser uma prática que, na base, dispensa o instrumento, antecipar o som antes do mesmo acontecer fisicamente serve como ferramenta metacognitiva, ou seja, isto está soando como eu imaginei? Se não, como chegar a esse som que tenho na cabeça? Silva (2010) investigou o papel da leitura cantada (solfejo) no desenvolvimento da audiação. Apesar de não ser muito claro quais hábitos levaram os entrevistados a desenvolver a audiação, o solfejo foi o único citado por todos. Os entrevistados também citaram aulas de percepção, improvisação, tocar de ouvido e composição (fora do instrumento).

O último conceito citado na descrição da arquitetura cognitiva e ainda não tratado aqui é a transferência de conhecimento. Como visto, por ele compreendemos uma informação geral armazenada que será utilizada em outro contexto (recontextualização) para desenvolver um novo conhecimento. Muito diferente de se lembrar de um conhecimento já aprendido, a transferência pressupõe a criação de novos conhecimentos a partir de uma informação aplicável a várias situações (HEROUX, 2006). Para exemplificar, no caso da leitura, se alguém lê um Sol no centro do pentagrama escrito com uma mínima e depois é capaz de ler uma mínima de Lá, o mesmo não realiza uma transferência, mas sim utiliza um co- 
nhecimento já anteriormente aprendido. A transferência é um processo mais profundo que pressupõe a solução de problemas, a construção de novos conhecimentos e a modificação da memória de longo prazo (MLP). Assim, a partir de conhecimentos teóricos sobre tom e semitom, por exemplo, um aluno de violão que sabe a posição da nota Dó no braço do instrumento (conhecimento já aprendido) e quer descobrir onde se encontra o Dó\# (conhecimento a aprender), sabendo que cada casa no braço do violão está a uma distância de um semitom pode supor que a próxima nota que virá após esse Dó é um Dó\#. Ou um aluno de piano que sabe as notas naturais (teclas brancas) sabendo que as teclas pretas estão a uma distância de semitom, também será capaz de descobrir os sustenidos e bemóis que estão entre as brancas. Então, providos de conhecimentos generalizáveis, esses alunos são capazes de descobrir sozinhos onde se encontram as notas nos seus instrumentos através da transferência de conhecimento.

Alguns métodos/livros de leitura também fazem uso de táticas de transferência. Richman (1985, p. 16) ao apresentar as linhas e espaços suplementares ao piano pede ao aluno que considere a última nota do pentagrama como referência para descobrir as suplementares. Maydwell (2003, p. 24) também falando sobre linhas e espaços suplementares apresenta uma abordagem mais cinestésica, convidando o aluno a colocar o dedo 1 para a primeira linha suplementar (nota lá) e fazer uma abertura de nona com o dedo 5. Assim, cada um dos dedos ficará sobre as linhas suplementares, isto é, a uma distância de terça, auxiliando a posterior descoberta das notas nos espaços. Bogo (2013, p. 48) ao apresentar seus estudos de região visando trabalhar armaduras de clave no violão reforça - baseado na transferência de conhecimento - a necessidade de começarmos pelas notas naturais que servirão de base para descobrir as cromáticas. Essas práticas mostram que, ao invés de criar regras desprovidas de lógica, o professor pode fixar bases sólidas e conhecimentos transferíveis para que o aluno amplifique sua MLP de maneira autônoma.

\section{Considerações finais}

A simples descrição do nosso processo cognitivo pode influenciar nossa maneira de ensinar/aprender a leitura musical, levando-nos, por exemplo, a compreender os limites da memória de trabalho (MT) e a importância dos chunks; a automatização dos movimentos; e a organização entre os três tipos de conhecimento (declarativo, procedural e condicional) visando assim uma melhor recuperação dos conhecimentos adquiridos. Comparações entre leitores experientes e iniciantes mostraram que os primeiros tendem a ler nota por nota, enquanto os mais experientes são capazes de dar significação mais profunda a uma partitura, tendo, desta forma, uma resposta mais automatizada ao estímulo visual. Apesar de não ser tão claro quando e como um conhecimento se automatiza, conceitos como codificação dupla, transferência e o uso táticas metacognitivas se mostram bons auxiliares da memorização, e por consequente, da aprendizagem. Neste contexto, o professor se apresenta como uma importante peça desse processo, guiando as práticas relacionadas aos conhecimentos procedurais/condicionais e criando conhecimentos declarativos transferíveis com o objetivo de dar maior autonomia a seus estudantes. Assim, os exemplos citados na sessão "influência na prática pedagógica” que longe de encerar o assunto sobre os hábitos no ensino-aprendizagem da leitura musical se apresentam como bons caminhos a serem explorados e posteriormente ampliados. 


\section{Notas}

1 "Sight reading means performing from a score without any preceding practice on the instrument of that score, to perform a prima vista”. (todas as traduções são do autor)

2 Termo geralmente mantido em inglês, faz referência a maneira como reagrupamos informações em unidades menores. Por exepmlo, a maneira como dividimos o numero de telefone $(2+4+4)$ ou o CPF $(3+3+3+2)$ ou a capacidade de reconhecer um grupo de notas como um acorde, uma sequência como uma escala etc. Na leitura textual, ao invés de lermos letra por letra (como fazem as crianças quando aprendem a ler), tendemos a ler mais por sílabas ou mesmo palavras inteiras. Para exemplificar esse fato, inverti duas letras da palavra "exemplo" acima e é muito fácil isso ter passado despercebido.

3 O eye-hand span é a distância média entre onde a vista olha e onde tocamos. Para Furneuax e Land essa distância é medida em notas e em segundos. Assim, os autores criaram dois índices: o índice tempo: quantos segundos há, em média, entre o que tocamos e o que olhamos; e o índice unidade-nota: quantas notas em média - acordes ou notas simples são contados como uma unidade. O índice tempo foi o mesmo para todos os níveis (cerca de 1 seg.). Por outro lado, o índice nota foi maior entre os melhores leitores (1,4 notas a mais). Isso quer dizer que, em média, os profissionais decodificaram 1,4 notas a mais que os amadores. Em números reais, profissionais leram 3,8 notas à frente da mão enquanto amadores leram 2,4. Isto nos dá uma ideia de quanta informação podemos guardar na MT durante uma tarefa de leitura.

4 Em informática, buffer representa a área de armazenamento temporário de dados à espera de processamento. Disponível em: http://michaelis.uol.com.br/busca?r=0\&f=0\&t=0\&palavra=buffer. Acesso em: 4 de julho de 2016.

5 "est de faire en sorte que les connaissances qui peuvent être automatisées le soient le plus rapidement possible afin que l'élève puisse employer ses unités de mémoire de travail aux éléments les plus significatifs de la tâche”.

6 Como: Goolsby, Eye movement in music reading (1994); Truitt et all., The perceptual spam and the eye-hand spam in sight-reading music (1997); Waters and Underwood, Eye movement in a simple reading music test (1998); Waters et all., Studying expertise in music reading (1997).

7 O tempo de duração no qual os olhos ficam parados em um local específico da partitura.

8 Como: Sloboda (2005 p. 36), Water and Underwood (1998 p. 35) e Fine, Berry and Rosner (2006 p. 440).

9 "servent en effet à rendre opérationnelles les connaissances déclaratives".

10 "ce n'est que dans l'action et par celle-ci que leur acquisition a le plus de probabilité de se produire”.

11 "consiste donc à rendre la séquence d'action disponible au champ perceptif de l'élève".

12 "consulter chaque fois que cela est nécessaire dans l'action".

13 "L'enseignant stratégique va donc placer l'élève dans un contexte de pratique guidé où il doit effectuer la connaissance procédural d'un but à l'autre”.

14 Para uma retrospectiva de estudos sobre Dual Code Theory ver Paivio, A. (1991). Dual coding theory: Retrospect and current status. Canadian Journal of Psychology/Revue canadienne de psychologie, 45(3), 255.

15 "Calling out impresses information on the memory, gives more control and enables the student to learn more quickly".

16 "The repeated saying of each note encourages a quick memorization".

\section{Referências}

ANDERSON, John Robert. Cognitive psychology and its implications. 2. ed. New York: Freeman, 1985. $472 \mathrm{p}$.

ANDRETTA, Ilana et al. Metacognição e Aprendizagem: como se relacionam? Psico, Porto Alegre, v. 41, n. 1, p. 7-13, 2010.

BERLIN, Boris; CHAMPAGNE, Claude. Practical Sight Reading Exercises for Piano Students. Book 1. Los Angeles: Alfred Music Publishing, 1958. 20 p.

BOGO, Danilo. Lecture à vue en régions aiguës à la guitare: L'élaboration d'un plan de travail pour favoriser des automatismes de lecture. Trabalho de pesquisa para obtenção do grau de Doutor em Música (D. Mus.). Université de Montréal, 2013. Montreal: UdeM, 2013. 113 p.

COMEAU, Gilles. L'apprentissage de la lecture musicale. Revue de Recherche en éducation $\mathrm{Mu}$ sicale, Laval, v. 28, p. 83-104, 2010. 
DEHAENE, Stanislas. Neurones de la lecture (Les): La nouvelle science de la lecture et de son apprentissage. Paris: Odile jacob, 2007. 478 p.

FIREMAN, Milson Casado. Leitura à primeira vista ao violão: A influencia da organização do material de estudo. Tese de Doutorado. Salvador: Universidade Federal da Bahia, 2010. 225 p.

FURNEAUX, S.; LAND, M. F. The effects of skill on the eye-hand span during musical sight-reading. Proceedings of the Royal Society of London B: Biological Sciences, Londres, v. 266, n. 1436, p. 2435-2440, 1999.

GABRIELSSON, Alf. Music performance research at the millennium. Psychology of music, v. 31, n. 3, p. 221-272, 2003.

GORDON, Edwin E. All about audiation and music aptitudes. Musical Educators Journal, Virginia, vol. 86, n. 2, p. 41-44, sep. 1999.

HÉROUX, Isabelle. L'apport de la psychologie cognitive dans l'élaboration d'un outil didactique pour favoriser l'apprentissage de la guitare au niveau collégial. Thèse de Doctorat (Ph. D.). Université Laval, 2006. Québec: Université Laval, 2006. 237 p.

HUNT, Oliver. Musicianship \& sight reading for guitarists. London: Musical new services Ltd., 1977. $67 \mathrm{p}$.

LEHMANN, Andreas C.; McARTHUR, Victoria. Sight-reading. In: PARNCUTT, Richard; McPHERSON, Gary. The science and psychology of music performance: creative strategies for teaching and learning. New York: Oxford University Press, 2002. p. 135-150.

MADELLl, J., \& HÉBERT, S. Music reading and eye movements: Where do we look next? Music Perception: An Interdisciplinary Journal. v. 26, n. 2, p. 157-170, 2008.

MARZANO, Robert, J. et al. Dimensions of thinking: A framework for Curriculum and Instruction. Alexandria: Association for Supervision and Curriculum development, 1988. 162 p.

MAYDWELL, Faith. Sight Reading Skills: A Pianist's Guide for Learning to Read Music Accurately and Expressively. Perth: New Arts Press of Perth, 2005. 56 p.

MILLER, George, A. The magical number seven, plus or minus two: some limits on our capacity for processing information. Psychological review, Washington, vol. 63, p. 81-97. 1956.

PAIVIO, Allan. Perceptual comparisons through the mind's eye. Memory \& Cognition, London, v. 3, n. 6, p. 635-647, 1975.

RICHMAN, Howard. Super Sight-Reading Secrets. 3. ed. Reseda: Sound Feelings Publ., 1985. $48 \mathrm{p}$.

SILVA, Ronaldo da. Leitura cantada: um caminho para a construção da audiação no músico profissional. Dissertação de Mestrado. Universidade de Campinas, 2010. Campinas: UNICAMP, 2010. 122 p.

TARDIF, Jacques. Pour un enseignement stratégique: L'apport de la psychologie cognitive. Québec: Éditions Logiques, 1992. 474 p.

Danilo Bogo - Graduado em violão pela Escola de Música e Belas Artes do Paraná e mestre em interpretação pela Universidade de Montreal (Canadá) onde atualmente faz seu doutorado na mesma área. Suas pesquisas na área da pedagogia instrumental dedicam-se ao desenvolvimento da leitura à primeira vista no violão. Além de seus estudos de doutoramento, atualmente é técnico do curso de música na UNILA onde, entre outros trabalhos, arranja, transcreve e acompanha cantores. 